\title{
Lichen Planus in Down Syndrome: Treatment with Systemic Retinoid - an Observation
}

\author{
Mohammad A. Hye ${ }^{* 1}$, Siddhartha Shankar Dutta ${ }^{2}$
}

\begin{abstract} be treated with systemic Retinoid.

*1. Corresponding Author:

Dr. Mohammad A. Hye

Professor

Department of Dermatology

Jalalabad Ragib-Rabeya Medical College

Patantula Sylhet, Bangladesh.

E-mail: mohammadhye@hotmail.com

2. Dr. Siddhartha Shankar Dutta

Assistant Profesor

Department of Dermatology

Sylhet M.A.G Osmani Medical College.
\end{abstract}

Introduction: Down syndrome $(D S)$ is the most common congenital abnormality affecting numerous organs and is associated with an increased incidence of many cutaneous diseases. Lichen Planus (LP) is a quite uncommon disease and associated with many immunologically altered condition. DS is also a medical condition with altered immune function. So, a higher research of LP associated with DS is very important for better understanding of both the diseases and also for comprehensive medical care. Case Report: A 33 years old known patient of Down Syndrome presented with signs and symptoms of LP is reported in this study. The diagnosis of LP was confirmed by histopathological study. She revealed a treatment history of several course of topical and systemic steroid since last 2 years for treatment of LP without any satisfactory outcome. After proper counseling we prescribed her systemic Acitretin (25 mg) daily for 3 months. She was examined every month for subsequent 3 months and was observed very satisfactory result. There was no relapse within one year after discontinuation of treatment. Discussion: We describe an adult patient with Down syndrome, associated with lichen planus (LP). LP is an inflammatory muco-cutaneous disease and benign in nature. However, some varieties of LP may cause considerable discomfort and need various systemic treatment. We treated the patient with systemic Retinoid with satisfactory result. Conclusion: LP associated with DS is a rare condition. It may

Keywords: Lichen planus, Acitretin, Down syndrome.

Number of Figures: 04; Number of References: 13; Number of Correspondence:03.

\section{Introduction:}

Down syndrome (DS), also known as trisomy 21, is an autosomal chromosomal disorder caused by the presence of all or part of a third copy of chromosome 21. It is typically associated with physical growth delays, characteristic facial features and mild to moderate intellectual disability. Down syndrome is one of the most common chromosomal abnormalities in humans with a birth incidence of approximately 1 in 1000 live birth ${ }^{1}$. The cutaneous manifestations of DS are numerous ${ }^{2,3,4,5,6}$. Common associated condition are: xerosis, atopic dermatitis, seborrheic dermatitis, cutaneous infections, alopecia areata, vitiligo, syringoma, elastoses, keratoderma palmaris et plantaris, pityriasis rubra pilaris etc. We describe an adult patient with Down syndrome, associated with lichen planus (LP). LP is an inflammatory muco-cutaneous disease characterized by shiny, flat-topped papules and plaques. It affects

around $1 \%$ of the population. The disease is usually self-limiting and benign in nature. However, some varieties of LP may cause considerable discomfort and recalcitrant in nature. Owing to advances in medical care and changes in attitude, the life expectancy of the DS patients is improving. A good number of research papers is published in medical literature regarding physical and psychological aspects of this disease. But papers related to LP and other cutaneous aspects of DS are not enough in number. Still, there is no published report on LP associated with DS. But LP is a disease which significantly affect quality of life of patient. The disease is also associated with many immunologically altered condition ${ }^{7}$. DS is also a medical condition with altered immune function ${ }^{4,8}$. So, an appreciation and higher research of LP associated with DS is very important for comprehensive medical care as well as quality of life of these patients.

\section{Case Report:}

A 33 years old Bangladeshi female presented with flat topped, violaceous papules and plaques in flexor surface of wrist, trunk and foot for last 2 (two) years. Plaques in foot were polymorphic in shape, $1.5 \mathrm{~cm}$ to $2 \mathrm{~cm}$ in diameter with wickham's striae in surface [Fig:1].

The lesions were slightly hypertrophic and signs of scratching were seen. However, lesions in wrist [Fig-2] and trunk were smaller in size. She complained of severe itching. Her treatment history revealed that she was prescribed both topical and systemic steroid several times with partial outcomes and recurrences.

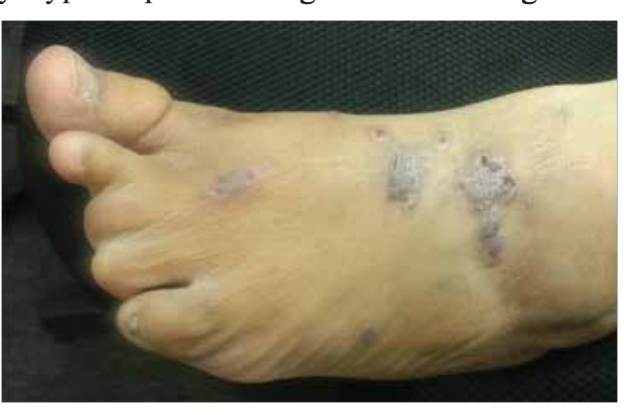

Figure-1: LP lesions in feet. 


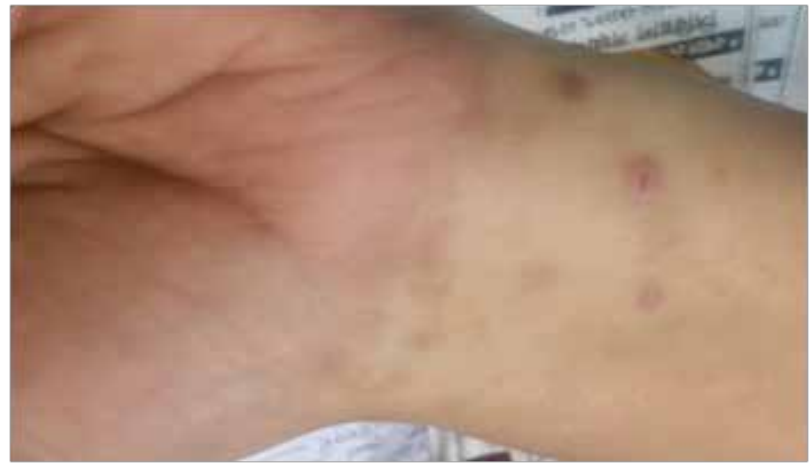

Figure-2: LP lesions in wrist and forearm.

Her physical appearance was compatible with that of DS and following features were observed: epicanthic fold, brachicephaly and depressed nasal bridge, upward angle of eyes, short broad neck and widened hands and foot and shortening of 4 (four) lateral toes. Routine laboratory data were between normal ranges. Her liver and kidney function parameter were within normal range. Histopatholgical study revealed hyperkertatosis, hypergranulosis, vacuolar degeneration of basal layer of epidermis and inflammatory cell infiltrate in upper dermis [Fig:3,4]. These findings are compatible with lichen planus. Her lipid profile was within normal limit. An interview with her family revealed that she had learning disability otherwise she was psychologically sound; She had only one brother and nobody of her family members had any relevant clinical conditions.

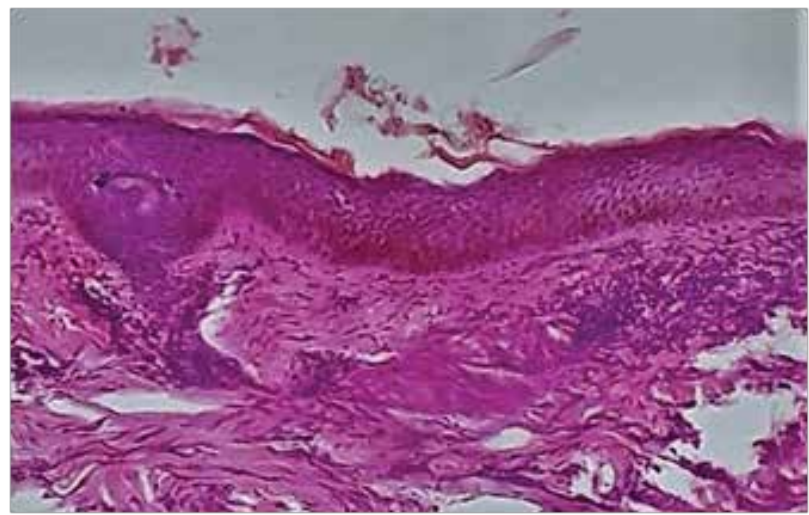

Figure-3: Histopathological feature (H\&E staining $100 \mathrm{xs}$ ).

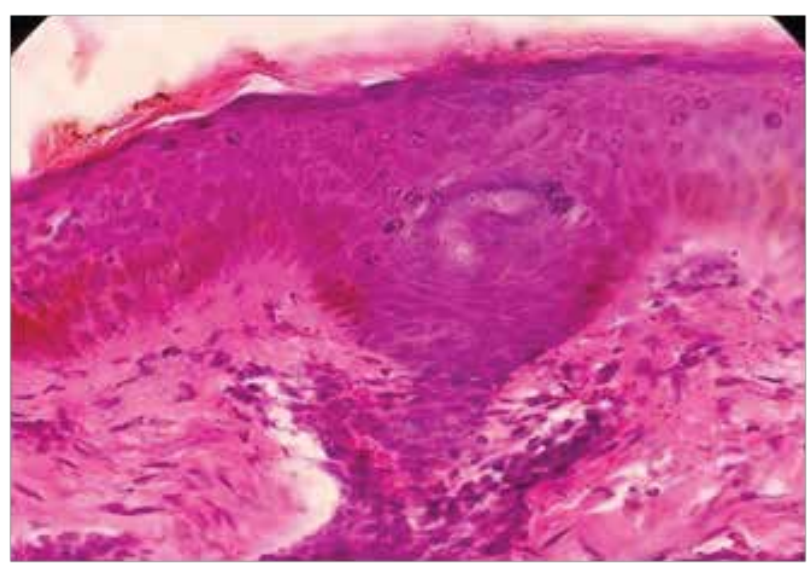

Figure-4: Histopathological feature (H\&E staining 400x).
She was a diagnosed case of DS and received several therapies in different institution by both internist and dermatologist. Her past history revealed that she had frequent episodes of bacterial and fungal infection since childhood. She revealed a treatment history of several course of topical and systemic steroid since last 2 yrs without any satisfactory outcome.

After proper counseling we prescribed her systemic Acitretin $(25 \mathrm{mg})$ daily for 1 month. She was examined after 1 month and we found her lesions were significantly cured with less intensity of itching. She was prescribed again for Acitretin (25mg) for consecutive 2 month after evaluation of her relevant laboratory parameters. She attended after 1 month with $90 \%$ clearance of lesions. In her follow up visit after I month, she was found fully cured. Patient did not complain of any significant side effects of the drugs. There was no relapse within one year after discontinuation of treatment.

\section{Discussion:}

Few case reports on lichen nitidus with DS were reported in literature but cutaneous LP associated with DS is not reported until now.

LP is one of the common disease in dermatology. The overall prevalence of lichen planus in the general population is about $0.1-4.0 \%{ }^{9}$. It generally occurs more commonly in females, in a ratio of 3:2, and most cases are diagnosed between the ages of 30 and 60 , but it can occur at any age 9

Pathogenesis of LP is not fully understood. However, there is a general consensus that LP is an immunologcally-mediated disease, where basal cell damage occurs due to a complex interaction between keratinocytes, Langerhan's cells and $\mathrm{T}$ cells ${ }^{7}$.

The LP with DS is not a recognized association. However, it is shown in different studies that cutaneous diseases are more frequent in patients of DS than normal population. More ever, it is reported that immune-mediated diseases like atopic dermatitis, psoriasis, seborrheic dermatitis etc are more frequent in patients of $\mathrm{DS}^{4}$.

LP is usually a self-limiting benign disease some form of the disease may persist for a long duration and may cause a range of morbidity.

Without treatment, most lesions will spontaneously resolve within 6-9 months for cutaneous lesions, and longer for mucosal lesions ${ }^{10}$.

More aggressive forms of treatment are needed for the few recalcitrant variants of LP including hypertrophic type. Standard therapy for LP includes topical and systemic steroids, retinoids and PUVA. Acitretin has shown a relatively good efficacy in the treatment of Hypertrophic $\mathrm{LP}^{11,12,13}$

In our case, patient was symptomatic, and she was treated with systemic steroid without satisfactory outcome. So, patient had a choice for systemic retinoid and we observed a very good result with these drugs. 


\section{Conclusion:}

In the medical literature, there is no research report on LP associated with DS. We presented the case to draw attention of the concerned health professional for more research in this arena. At present, the patients of Down syndrome are enjoying a longer life span than before; they deserve the best medical care and quality of life in this $21 \mathrm{st}$ century.

Conflict of Interest: None.

Acknowledgement:

Prof Dr. Mohammad Kamal, Ex-Professsor of BSSMU for his kind support and for histopathology.

\section{References:}

1. Weijerman, ME; de Winter JP. The care of children with Down syndrome. European journal of pediatrics. 2010; 169 (12): 1445-52.

https://doi.org/10.1007/s00431-010-1253-0

\section{PMid:20632187 PMCid:PMC2962780}

2. Carmelo Schepis, Concetta Barone, Maddalone Sirgnsa. An Updated Survey in Skin Conditions in Down Syndrome. Dermatology. 2002; 205: 234-8.

https://doi.org/10.1159/000065859

PMid:12399669

3. Dourmishev A. Mitev V, Pramatarov K, Schartz RA. Cutaneous aspect of Down Sundrome. Cutis. 2000; 66: 420-4.

4. Barankin B, Guenther L. Dermatological manifestations of Down syndrome. J Cutan Med Surg. 2001; 5: 289-93. https://doi.org/10.1177/120347540100500401

https://doi.org/10.1007/s102270000021

\section{PMid:11907837}

5. Brown AC, Olkowaski ZL, Mklaren JR, Kutner MH. Alopecia areata and vitiligo associated with Down nsyndrome. Arch Dermatol. 1977; 113: 1296.

https://doi.org/10.1001/archderm.1977.01640090144032

https://doi.org/10.1001/archderm.113.9.1296b

https://doi.org/10.1001/archderm.113.9.1296

PMid: 143244
6. Hazini AR, Rongioletti F, Rebora A. Pityriasis rubra pilaris and vitiligo in Down syndrome. Clin Exp Dermatol. 1988; 13: 334-5.

https://doi.org/10.1111/j.1365-2230.1988.tb00716.x

PMid:2978467

7. Shiohara T, Mariya N, Tanaka Y. Immunopathological study of lichenoid skin diseases. Correlation between HLA-DR positive keratinocytes or langerhans cells and epidermotropic T cells. J Am Acad Dermatol. 1988; 18: $67-74$

https://doi.org/10.1016/S0190-9622(88)70011-0

8. MAA Kuters, RH Verstegen, EFA Gemen, E de Vries. Intrinsic defect of the immune system in children in Down syndrome: a review. Clin Exp Immunol. 2009 May;(2): 189-193.

https://doi.org/10.1111/j.1365-2249.2009.03890.x

PMid:19250275 PMCid:PMC2759463

9. Le Cleach, Laurence; Chosidow, Olivier "Lichen Planus". New Eng Jourof Med. 2013 Feb; 366 (8): 723-32. https://doi.org/10.1056/NEJMcp1103641

PMid:22356325

10. Scully, C.; El-Kom, M. (1 July 1985). Lichen planus: review and update on pathogenesis. Journal of Oral Pathology and Medicine. 1985 Jul. 14 (6): 431-58.

https://doi.org/10.1111/j.1600-0714.1985.tb00516.x

11. Oliver GF, Winklemann RK. Treatment of lichen planus. Drugs. 1993; 45:56-65.

https://doi.org/10.2165/00003495-199345010-00006

PMid:7680985

12. Alamri A, Alsenaid A, Ruzicka T, Wolf R. Hypertrophic Lichen Planus- Successful treatment with acitretin. Dematol Ther. 2016 May; 29(3): 173-6.

https://doi.org/10.1111/dth.12337

PMid:26809380

13. Vazirnia A, Cohen P. Acitretin for the management of genealized cutaneous lichen planus. Dermatol Online J. 2014 Sep; 20(9): 25244164. 